\title{
Pseudotumor Cerebri Presenting Unilateral Papilledema Associated with Iron-deficiency Anemia
}

\section{Pseudotumor cerebral apresentando papiledema unilateral associado a anemia ferropriva}

\author{
Fernando Antônio de Oliveira Costa ${ }^{1}$ Othello Moreira Fabião Neto ${ }^{1}$ Guilherme Gago ${ }^{2}$ \\ Otávio Garcia Martins ${ }^{3}$ Frederico de Lima Gibbon ${ }^{2}$ Leonardo Mendes Nogueira ${ }^{2}$ \\ ${ }^{1}$ Escola Paulista de Medicina, Pelotas, Rio Grande do Sul, Brazil \\ 2 Universidade Católica de Pelotas, Pelotas, Rio Grande do Sul, Brazil \\ ${ }^{3}$ Universidade Federal de Pelotas, Pelotas, Rio Grande do Sul, Brazil \\ Arq Bras Neurocir 2018;37:58-62.

\begin{abstract}
Address for correspondence Otávio Garcia Martins, Medical Student, Department of Specialized Medicine, Universidade Federal de Pelotas, Av Duque de Caxias 255, apto 201 Bloco E - Pelotas, RS, Brasil CEP: 96030-000 (e-mail: otvmartins@gmail.com).
\end{abstract}

\author{
Abstract \\ Keywords \\ - pseudotumor cerebri \\ - idiopathic intracranial \\ hypertension \\ - unilateral \\ papilledema \\ - iron-deficiency \\ anemia
}

\section{Resumo \\ Palavras-chave \\ - pseudotumor cerebral \\ - hipertensão intracraniana idiopática \\ - papiledema unilateral \\ - anemia ferropriva}

Pseudotumor cerebri is a relatively common pathology that is characterized by intracranial hypertension in the absence of mass lesions. It commonly affects young and obese women, and its presentation with visual loss and bilateral papilledema is well-described in the literature. We present a case of a 44-year-old, non-obese, female patient presenting with unilateral papilledema and iron-deficiency anemia. This case emphasizes this unusual presentation and the rare association with iron deficiency.
O pseudotumor cerebral é uma patologia relativamente comum, caracterizada pela hipertensão intracraniana na ausência de lesões causando efeito de massa. Frequentemente afeta mulheres jovens e obesas, e sua apresentação, com perda do campo visual e papiledema bilateral, é bem descrita na literatura. Nós apresentamos um caso de uma paciente de 44 anos, não obesa, com papiledema unilateral e anemia ferropriva. Esse caso destaca essa apresentação incomum e a rara associação com a deficiência de ferro.

\section{Introduction}

Pseudotumor Cerebri (PTC), also known as idiopathic intracranial hypertension $(\mathrm{IIH})$ or benign intracranial hypertension (BIH), is a medical condition characterized by increased intracranial pressure (ICP) without evidence of intracranial mass, hydrocephalus, infection or hypertensive encephalopathy. It usually affects overweight women of childbearing age, and its pathogenesis is uncertain. ${ }^{1-4}$ Some studies indicate that this is an absorbing problem at the arachnoid level, ${ }^{4}$ but there is much controversy in the literature. The diagnosis of PTC is based on clinical symptoms and signs, normal findings in imaging studies, increased cerebrospinal fluid (CSF) opening pressure, and exclusion of other probable pathologies. ${ }^{5}$ received

September 29, 2017

accepted

December 18, 2017

published online

March 8, 2018
DOI https://doi.org/

$10.1055 / \mathrm{s}-0038-1625979$.

ISSN $0103-5355$.
Copyright $\odot 2018$ by Thieme Revinter

Publicações Ltda, Rio de Janeiro, Brazil
License terms

(c) $(1) \$$ 


\section{Case Report}

A 44-year-old female patient, who was previously healthy, underwent an abdominoplasty under epidural anesthesia. The surgery was uneventful, and the patient was discharged in good general condition $\sim 24$ hours after the procedure. About 48 hours after discharge, the patient sought care with an ophthalmologist due to loss of vision in the right eye. In addition, she had a sudden headache of strong intensity and holocranial in nature, which was associated with an emetic episode, diplopia and dizziness. Papilledema was observed in the ophthalmologist's office, and the patient was referred to our clinic.

Upon admission, the general physical examination revealed a heart rate of $120 \mathrm{bpm}$, and the carotid auscultation revealed bilateral bruits. The body mass index (BMI) was $28 \mathrm{~kg} / \mathrm{m}^{2}$. A neurological examination showed a reduction in visual acuity in the right eye, maintaining only the perception of movement. In addition, an edema was found in the ipsilateral papilla. The other aspects of the neurological examination did not suggest other abnormalities.

Due to the rapid onset of symptoms, the patient underwent magnetic resonance imaging (MRI) with and without contrast, which revealed only relatively small ventricles (-Fig. 1). In addition, arterial and venous angio-MRIs were performed, and the results were considered normal (-Fig. 2). After the radiological investigation, the patient was admitted for a clinical investigation.

The laboratory investigation revealed levels of serum hemoglobin of $5.2 \mathrm{~g} / \mathrm{dL}$. In addition, the hemogram showed microcytosis and hypochromia. The cardiologic evaluation revealed no abnormalities. A lumbar puncture was performed, and the opening pressure was of $34 \mathrm{~cm} \mathrm{H}_{2} \mathrm{O}$. The diagnosis of $\mathrm{BIH}$ was made, and the treatment for anemia associated with blood transfusion and iron supplements was initiated. Due to severe vision loss, intravenous (IV) methyl-

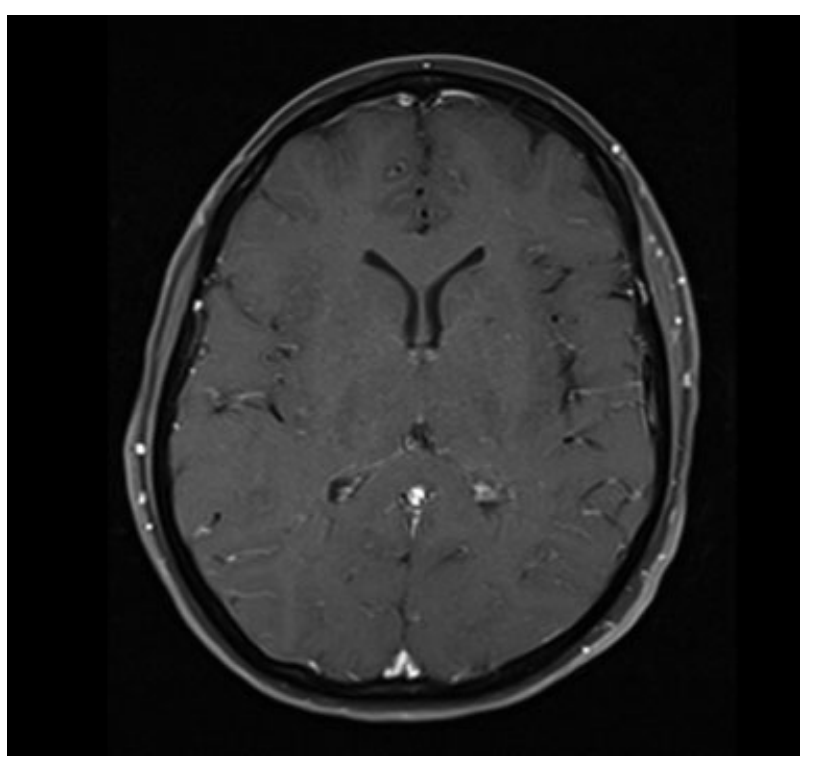

Fig. 1 Normal magnetic resonance imaging (MRI) scan of the brain. T1-weighted, axial plane.

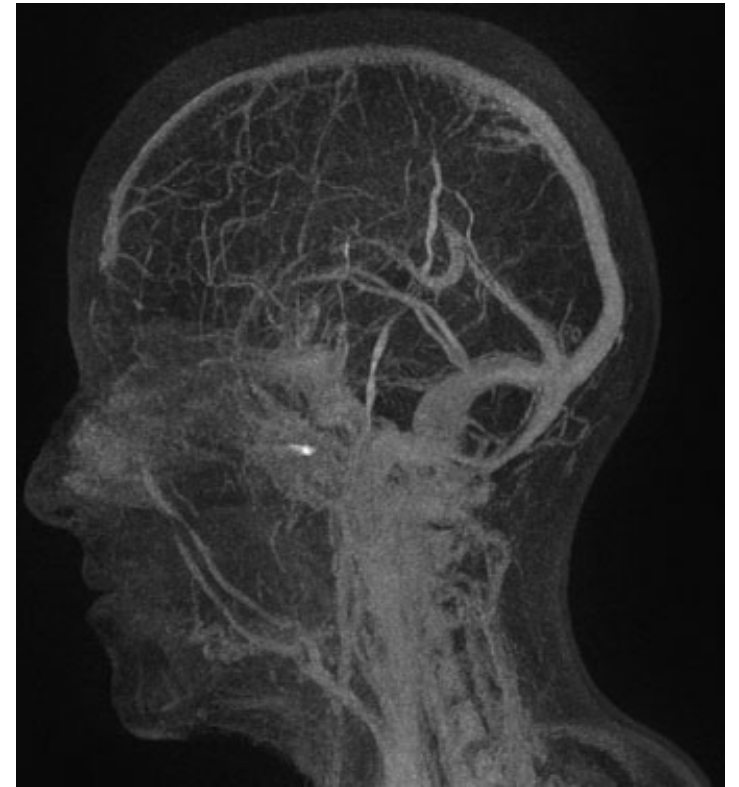

Fig. 2 Normal three-dimensional gadolinium-enhanced magnetic resonance venogram (MRV), sagittal view.

prednidisolone $250 \mathrm{mg}$ was prescribed every 6 hours associated with acetazolamide $1,000 \mathrm{mg}$ twice a day.

The patient presented a dramatic response to the treatment, with complete improvement of the symptoms, except for the visual deficit, which remained unchanged. She was discharged 72 hours after admission, with no complaints, maintaining only the visual deficit. The ophthalmologic evaluation after discharge suggested a probably irreversible lesion in the right optic nerve.

\section{Discussion}

Pseudotumor cerebri is a disorder that affects overweight/ obese women of childbearing age, and it has an annual incidence of $1-2 / 100,000$ inhabitants among the general population. ${ }^{4,6-8}$ However, it is a disease that can affect men, children, the elderly, and patients who are not obese. $^{9-13}$ When it affects younger people, gender and weight appear to have no significance in the incidence. ${ }^{14,15}$

A considerable number of systemic conditions, drugs and vitamin deficiency have been associated with PTC. One peculiar condition mentioned in the literature is iron-deficiency anemia, whose prevalence in patients diagnosed with PTC is $\sim 10 \%{ }^{16-19}$ However, the statistically significant association between PTC and the other conditions is unclear in many cases.

Typically, PTC is a self-limited but recurrent pathology, with a recurrence rate ranging from $9-43 \%{ }^{6,7}$ Severe visual deficits develop in $4-12 \%$ of the patients, although there is no relation to the duration of the symptoms, the degree of the papilledema, headache or the number of recurrences. ${ }^{20}$

Due to the intrinsic mechanisms of the body, it is conclusive that the increase in intracranial pressure is originated in at least one of the following body components: CSF, blood, interstitial fluid or cerebral cells. Cerebrospinal fluid 
production is relatively constant and independent of its internal pressure, at least to some extent. Hence, the increase in pressure is not quickly normalized with the reduction in CSF production, facilitating the development of the condition, once the process is initiated. ${ }^{21-23}$ An increase in CSF production has been suggested in $\mathrm{PTC}^{24}$ but there is no evidence to support such a theory, or any structural changes in the choroid plexus, such as hypertrophy. There is some evidence to suggest that CSF production is normal in PTC. ${ }^{25}$

Most of the focus on PTC pathogenesis studies has been on resistance to the CSF absorption mechanism. Several studies involving CSF infusion have been published, and all showed a greater resistance to CSF absorption in PTC. ${ }^{26-28}$ Gjerris et al found a lower CSF flow in 12 out of 14 patients with PTC, with 2 normal values measured after the beginning of the treatment. ${ }^{27}$ Janny et al demonstrated resistance to the flow in all 16 patients with PTC studied. ${ }^{28}$ Although most studies have focused on the intracranial CSF compartment, new imaging techniques using dynamic contrast phases suggest that there is an increase in extraventricular CSF volume and a decrease in jugular venous output in PTC compared with control individuals. ${ }^{29}$ Alterations in spinal canal compliance may be a contributory factor. ${ }^{30}$ It seems likely that the decrease in absorption is the core of the pathophysiology, possibly due to a local effect involving the epithelial membrane of the CSF output routes.

Magnetic resonance venography demonstrates that the majority of PTC patients have venous sinus stenosis. ${ }^{31}$ It is unclear if such stenosis is the cause or consequence of PTC, although cases of demonstrated resolution of collapsible venous sinus segments after CSF drainage and pressure normalization have suggested that the latter is true. ${ }^{32,33}$ Cerebral venous sinus narrowing usually develops at the transverse sinuses or transverse/sigmoid junction, and may be bilateral or unilateral. ${ }^{34}$

For the cases of venous sinus stenosis, the placement of a stent seems to be a good therapeutic option. In a study conducted with a large cohort composed of 52 patients who underwent unilateral cerebral venous sinus stenting, all patients had resolution of the papilledema; 23 out of 30 patients had resolution of the visual field loss, and headache only persisted in 3 patients. ${ }^{34}$

\section{Etiology - Association with Iron-deficiency Anemia}

Even though the condition is also known as idiopathic intracranial hypertension (IIH), the nomenclature of pseudotumor cerebri (PTC) syndrome is more inclusive, because it covers both the idiopathic cause and the secondary etiologies.

Giuseffi et al $^{17}$ reported a prospective controlled study adjusted for age and sex that investigated the associations of diseases and drugs in PTC. They found that iron-deficiency anemia was not more common in patients with intracranial hypertension than in controls. This result was similar to the ones published by Ireland et al, ${ }^{16}$ who reported that irondeficiency anemia was more frequently found in the control group. However, the association between the two conditions seems to be strong, since PTC symptoms resolve when the patient is treated for iron-deficiency anemia, as it happened in the case presented here. ${ }^{17,35}$

In a study by Mollan et al, ${ }^{35} 8$ patients with PTC and irondeficiency anemia were reported, and 7 of them had remission of the symptoms with the treatment for anemia. The patients were treated with blood transfusion and oral iron replacement, depending on the severity of the symptoms.

\section{Clinical Features}

The most prevalent symptoms in PTC are headache (88\%), transient visual obscurations (70\%), pulsatile tinnitus (56\%), nausea (32\%), diplopia (28\%), and visual loss (14\%). The presentation can be acute with recurrences or chronic (26-32\%). 8,19

The characteristics of the headache can be variable. Unilateral or bilateral headaches that are pulsatile and with a retro-ocular location have been reported. ${ }^{36}$ Transient visual obscurations occur in two thirds of the patients with papilledema, and they may be unilateral or bilateral. ${ }^{8}$ The frequency ranges from rare episodes to multiple cases per day. However, the presence of this symptom does not seem to be correlated with the severity of the disease. ${ }^{17,37}$ It is believed that pulsatile tinnitus represents vascular pulsations transmitted by the CSF to the venous sinuses at high pressure. ${ }^{38}$ When it occurs along with headache, it is highly suggestive of PTC. ${ }^{17,39,40}$

The principal signs of PTC are papilledema, visual field loss, and abducens nerve palsy.

Papilledema is generally symmetrical and bilateral, and is one of the hallmark features of PTC. ${ }^{41-43}$ The presence of unilateral papilledema is rare, and the degree of visual field loss is greater in the eye with the higher grade of papilledema. ${ }^{42}$ This uncommon unilateral commitment was present in our patient, and it was associated with the permanent loss of the visual field.

Abducens nerve palsy may present unilaterally or bilaterally, and it reflects the effect of the elevated intracranial pressure on this nerve, which has the largest intracranial pathway. ${ }^{19,44}$

In the presence of signs of intracranial hypertension, neuroimaging should be performed to discard a secondary cause, such as tumor, intracranial hemorrhage or venous sinus thrombosis. In the absence of altered imaging, lumbar puncture and CSF analysis are indicated to discard other causes. It is also necessary to request a blood count to verify the presence of anemia, a condition that may be associated with PTC. ${ }^{45}$

In general, the patients present spontaneous resolution of the symptoms within a year. Therefore, the interventional treatment is commonly suggested whether the patients are symptomatic or did not have resolution of the set. ${ }^{46-48}$ However, recurrence may occur in those patients who received the medical treatment, as well as in those who did not need it. In obese patients, weight loss has been associated with complete resolution of the papilledema. ${ }^{49,50}$ Weight loss has shown such good results that bariatric surgery has been studied as an option of treatment for obese patients. Nevertheless, this improvement may be too slow for cases of highly-threatened vision; thus, in these cases, pharmacological treatment would be helpful. ${ }^{50}$ The interventional treatment is based on fluid and 
salt restriction combined with diuretics. Acetazolamide, a carbonic anhydrase inhibitor, has been widely used to reduce the intracranial pressure with good results; therefore it seems to be a good drug to be administered as a first choice, even though no randomized clinical trial data have confirmed its effectiveness. A long-term follow-up study demonstrated that $60 \%$ of the patients had recurrent episodes during a period of 6.2 years; however, none of these episodes occurred during the time the patients were taking acetozalamide. ${ }^{51}$ Other drugs, such as furosemide, methazolamide and topiramate, have also been used to manage the symptoms, but they do not seem to be as effective as acetazolamide when used alone. Corticosteroids do not seem to be recommended as a routine choice of treatment, especially because of their relationship to weight gain, but in a critical situation, they may be useful to relieve the symptoms. $^{46,47,49,52}$

Additionally, as PTC appears to be related to different causes, it is plausible that the underlying cause is corrected. ${ }^{48}$ In our case, we prescribed acetazolamide and corticosteroid, since the patient presented a high risk of visual loss. We treated the patient for iron-deficiency anemia with ferrous sulfate. In the cases that cannot be managed with drugs, ventricle or lumbar-peritoneal shunts have been shown to be effective choices. However, some patients may develop chronic daily headaches, and this may be understood as shunt failure. ${ }^{47,49}$ Furthermore, if the condition cannot be managed only by pharmacological treatment or with a shunt, an optic nerve sheath fenestration is an option in order to preserve the visual function. ${ }^{46,47}$

\section{Conclusion}

Our case highlights an uncommon presentation of PTC with unilateral papilledema and the still poorly-understood association between iron deficiency and $\mathrm{BIH}$. As reported in the literature, our case presented a dramatic response to PTC symptoms with the treatment for iron-deficiency anemia. This response points to a possible association between these two conditions, but more studies should be conducted to elucidate this correlation.

Conflicts of Interest

The authors have no conflicts of interest to disclose.

\section{References}

1 Corbett J. Idiopathic intracranial hypertension. J Neuroophthalmol 2012;32(03):e4-e6

2 Corbett JJ. The 1982 Silversides lecture. Problems in the diagnosis and treatment of pseudotumor cerebri. Can J Neurol Sci 1983;10 (04):221-229

3 Daniels AB, Liu GT, Volpe NJ, et al. Profiles of obesity, weight gain, and quality of life in idiopathic intracranial hypertension (pseudotumor cerebri). Am J Ophthalmol 2007;143(04):635-641

4 Durcan FJ, Corbett JJ, Wall M. The incidence of pseudotumor cerebri. Population studies in Iowa and Louisiana. Arch Neurol 1988;45(08):875-877

5 Friedman DI. Idiopathic intracranial hypertension with Dan and beyond: the 2010 Jacobson Lecture. J Neuroophthalmol 2010;30 (04):380-385
6 Radhakrishnan K, Ahlskog JE, Garrity JA, Kurland LT. Idiopathic intracranial hypertension. Mayo Clin Proc 1994;69(02):169-180

7 Radhakrishnan K, Ahlskog JE, Cross SA, Kurland LT, O'Fallon WM. Idiopathic intracranial hypertension (pseudotumor cerebri). Descriptive epidemiology in Rochester, Minn, 1976 to 1990. Arch Neurol 1993;50(01):78-80

8 Wall M, George D. Idiopathic intracranial hypertension. A prospective study of 50 patients. Brain 1991;114(Pt 1A):155-180

9 Bruce BB, Kedar S, Van Stavern GP, Corbett JJ, Newman NJ, Biousse V. Atypical idiopathic intracranial hypertension: normal BMI and older patients. Neurology 2010;74(22):1827-1832

10 Soler D, Cox T, Bullock P, Calver DM, Robinson RO. Diagnosis and management of benign intracranial hypertension. Arch Dis Child 1998;78(01):89-94

11 Digre KB, Corbett JJ. Pseudotumor cerebri in men. Arch Neurol 1988;45(08):866-872

12 Lee AG, Golnik K, Kardon R, Wall M, Eggenberger E, Yedavally S. Sleep apnea and intracranial hypertension in men. Ophthalmology 2002;109(03):482-485

13 Johnston I, Kollar C, Dunkley S, Assaad N, Parker G. Cranial venous outflow obstruction in the pseudotumour syndrome: incidence, nature and relevance. J Clin Neurosci 2002;9(03):273-278

14 Balcer LJ, Liu GT, Forman S, et al. Idiopathic intracranial hypertension: relation of age and obesity in children. Neurology 1999;52 (04):870-872

15 Cinciripini GS, Donahue S, Borchert MS. Idiopathic intracranial hypertension in prepubertal pediatric patients: characteristics, treatment, and outcome. Am J Ophthalmol 1999;127(02):178-182

16 Ireland B, Corbett JJ, Wallace RB. The search for causes of idiopathic intracranial hypertension. A preliminary case-control study. Arch Neurol 1990;47(03):315-320

17 Giuseffi V, Wall M, Siegel PZ, Rojas PB. Symptoms and disease associations in idiopathic intracranial hypertension (pseudotumor cerebri): a case-control study. Neurology 1991;41(2 Pt 1):239-244

18 Tugal O, Jacobson R, Berezin S, et al. Recurrent benign intracranial hypertension due to iron deficiency anemia. Case report and review of the literature. Am J Pediatr Hematol Oncol 1994;16(03):266-270

19 Wall M, Kupersmith MJ, Kieburtz KD, et al; NORDIC Idiopathic Intracranial Hypertension Study Group. The idiopathic intracranial hypertension treatment trial: clinical profile at baseline. JAMA Neurol 2014;71(06):693-701

20 Rush JA. Pseudotumor cerebri: clinical profile and visual outcome in 63 patients. Mayo Clin Proc 1980;55(09):541-546

21 Sklar FH, Reisch J, Elashvili I, Smith T, Long DM. Effects of pressure on cerebrospinal fluid formation: nonsteady-state measurements in dogs. Am J Physiol 1980;239(03):R277-R284

22 Welch $K$. The principles of physiology of the cerebrospinal fluid in relation to hydrocephalus including normal pressure hydrocephalus. Adv Neurol 1975;13:247-332

23 Sahar A. The effect of pressure on the production of cerebrospinal fluid by the choroid plexus. J Neurol Sci 1972;16(01):49-58

24 Donaldson JO. Cerebrospinal fluid hypersecretion in pseudotumor cerebri. Trans Am Neurol Assoc 1979;104:196-198

25 Johnston I, Paterson A. Benign intracranial hypertension. II. CSF pressure and circulation. Brain 1974;97(02):301-312

26 Mann JD, Johnson RN, Butler AB, Bass NH. Cerebrospinal fluid circulatory dynamics in pseudotumor cerebri and response to steroid therapy. Neurology 1979;29:550

27 Gjerris F, Soelberg Sørensen P, Vorstrup S, Paulson OB. Intracranial pressure, conductance to cerebrospinal fluid outflow, and cerebral blood flow in patients with benign intracranial hypertension (pseudotumor cerebri). Ann Neurol 1985;17(02):158-162

28 Janny P, Chazal J, Colnet G, Irthum B, Georget AM. Benign intracranial hypertension and disorders of CSF absorption. Surg Neurol 1981;15(03):168-174

29 Alperin N, Ranganathan S, Bagci AM, et al. MRI evidence of impaired CSF homeostasis in obesity-associated idiopathic intracranial hypertension. AJNR Am J Neuroradiol 2013;34(01):29-34 
30 Alperin N, Lam BL, Tain R-W, et al. Evidence for altered spinal canal compliance and cerebral venous drainage in untreated idiopathic intracranial hypertension. Acta Neurochir Suppl (Wien) 2012;114:201-205

31 Farb RI, Vanek I, Scott JN, et al. Idiopathic intracranial hypertension: the prevalence and morphology of sinovenous stenosis. Neurology 2003;60(09):1418-1424

32 Rohr A, Dörner L, Stingele R, Buhl R, Alfke K, Jansen O. Reversibility of venous sinus obstruction in idiopathic intracranial hypertension. AJNR Am J Neuroradiol 2007;28(04):656-659

33 King JO, Mitchell PJ, Thomson KR, Tress BM. Manometry combined with cervical puncture in idiopathic intracranial hypertension. Neurology 2002;58(01):26-30

34 Kanagalingam S, Subramanian PS. Cerebral venous sinus stenting for pseudotumor cerebri: A review. Saudi J Ophthalmol 2015;29 (01):3-8

35 Mollan SP, Ball AK, Sinclair AJ, et al. Idiopathic intracranial hypertension associated with iron deficiency anaemia: a lesson for management. Eur Neurol 2009;62(02):105-108

36 Wall M. The headache profile of idiopathic intracranial hypertension. Cephalalgia 1990;10(06):331-335

37 Corbett JJ, Savino PJ, Thompson HS, et al. Visual loss in pseudotumor cerebri. Follow-up of 57 patients from five to 41 years and a profile of 14 patients with permanent severe visual loss. Arch Neurol 1982;39(08):461-474

38 Sismanis A, Butts FM, Hughes GB. Objective tinnitus in benign intracranial hypertension: an update. Laryngoscope 1990;100 (01):33-36

39 Wang SJ, Silberstein SD, Patterson S, Young WB. Idiopathic intracranial hypertension without papilledema: a case-control study in a headache center. Neurology 1998;51(01):245-249

40 Rudnick E, Sismanis A. Pulsatile tinnitus and spontaneous cerebrospinal fluid rhinorrhea: indicators of benign intracranial hypertension syndrome. Otol Neurotol 2005;26(02):166-168
41 Chari C, Rao NS. Benign intracranial hypertension-its unusual manifestations. Headache 1991;31(09):599-600

42 Wall M, White WN II. Asymmetric papilledema in idiopathic intracranial hypertension: prospective interocular comparison of sensory visual function. Invest Ophthalmol Vis Sci 1998;39 (01):134-142

43 Greenfield DS, Wanichwecharungruang B, Liebmann JM, Ritch R. Pseudotumor cerebri appearing with unilateral papilledema after trabeculectomy. Arch Ophthalmol 1997;115(03):423-426

44 Quattrone A, Bono F, Fera F, Lavano A. Isolated unilateral abducens palsy in idiopathic intracranial hypertension without papilledema. Eur J Neurol 2006;13(06):670-671

45 Biousse V, Rucker JC, Vignal C, Crassard I, Katz BJ, Newman NJ. Anemia and papilledema. Am J Ophthalmol 2003;135(04):437-446

46 Mark S. Greenberg. Handbook of Neurosurgery. Eighth. Vol. 81, The Yale journal of biology and medicine. New York: Thieme; 2008

47 Galgano MA, Deshaies EM. An update on the management of pseudotumor cerebri. Clin Neurol Neurosurg 2013;115(03): $252-259$

48 Thurtell MJ, Bruce BB, Newman NJ, Biousse V. An update on idiopathic intracranial hypertension. Rev Neurol Dis 2010;7(2-3): e56-e68

49 Wakerley BR, Tan MH, Ting EY. Idiopathic intracranial hypertension. Cephalalgia 2015;35(03):248-261

50 Johnson LN, Krohel GB, Madsen RW, March GA Jr. The role of weight loss and acetazolamide in the treatment of idiopathic intracranial hypertension (pseudotumor cerebri). Ophthalmology 1998;105(12):2313-2317

51 Kesler A, Hadayer A, Goldhammer Y, Almog Y, Korczyn AD. Idiopathic intracranial hypertension: risk of recurrences. Neurology 2004;63(09):1737-1739

52 Liu GT, Glaser JS, Schatz NJ. High-dose methylprednisolone and acetazolamide for visual loss in pseudotumor cerebri. Am J Ophthalmol 1994;118(01):88-96 